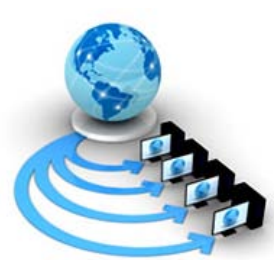

Volume 8, No. 8, September-October 2017

International Journal of Advanced Research in Computer Science

RESEARCH PAPER

Available Online at www.ijarcs.info

\title{
FUZZY BASED MULTI-METRIC PATH RANKING SCHEME FOR MULTIPATH ROUTING
}

\author{
Shalini Aggarwal \\ Assistant Professor \\ S.U.S. Govt. College, Matak Majri(Indri) \\ Karnal(Haryana), India
}

\author{
Pardeep Kumar \\ Associate Professor \\ Department of Computer Science \& Applications \\ Kurukshetra University \\ Kurukshetra (Haryana), India
}

\author{
Shuchita Upadhyaya \\ Professor \\ Department of Computer Science \& Applications \\ Kurukshetra University \\ Kurukshetra (Haryana), India
}

\begin{abstract}
The paper focuses on the design of multipath ranking scheme on the basis of multi-metric approach for computer networks. The scheme is based on fuzzy logic with the underlying assumption that multiple paths are known in advance with the link utilization of each link. The proposed scheme is using two metrics: hop count and link utilization. The link utilization value is based on the load and capacity of all the underlying links. The proposed scheme finds the ranking of the paths to select a quantum of paths for distributing loads over them. The proposed scheme finds the fuzzy values of each path using fuzzy controller. The path ranking and fuzzy value of each path provides a insight into the quality of the paths.
\end{abstract}

Keywords: ITMR; PLU; PRFC; Hop-count; Path ranking.

\section{INTRODUCTION}

OSPF Protocol in the Internet architecture tends to find a single best path between a source and destination pair. Efforts in the direction of exploring multiple paths have gained substantial prominence in literature. Inclination towards fault tolerance and congestion control makes multipath routing an alluring field of research.

The first major issue in multipath routing is to find multiple paths from a source to destination. After finding the multiple paths [1], the major bottleneck is to find better paths so that instead of using all possible paths, only a limited number of good path are used to keep overhead at a minimum. This paper is an attempt to find such a mechanism using fuzzy logic.In this paper, the paths have been ranked using fuzzy logic and better paths can be selected for data transmission on the basis of path ranks. The problem is to rank the input paths on the basis of link utilization value of each link in each path and the hop count of the paths.

\section{FUZZY LOGIC}

Fuzzy Logic [2] (FL) is a method of reasoning that resembles human reasoning. Fuzzy logic helps computers to take decisions related to problems having all possibilities of solutions lying in between "completely true" and "completely false" just like human reasoning.

Though Fuzzy Logic has been used at various places in many real world applications successfully, yet the use of Fuzzy Logic in computer networks is still very limited.

Today's computer networks are complex in nature and a fair number of uncertainties exist in the traffic conditions with unpredictable loads, available bandwidths, multiple links on a path with varying conditions of traffic on each link, etc. The reason for uncertainty is due to the fact that multiple metrics influence each other. Due to this fact these systems might behave randomly on different metrics that may be analyzed statistically but may not be predicted precisely. Thus fuzzy logic may fit in such situations. However, for a fuzzy system to work smoothly, fuzzy controllers and perceptive of fuzzy mathematics plays a significant role.

It has been analyzed in literature by [3], [4], [5], [6], and [7] that the results are better in terms of link delay, link utilization, path length, packet loss, throughput, bandwidth, communication cost, etc., when fuzzy mixed metric is used. A Fuzzy Controller [8] consists of four parts (a) fuzzification module, (b) rule base, (c) inference engine and (d) defuzzification module as displayed in figure 1 .

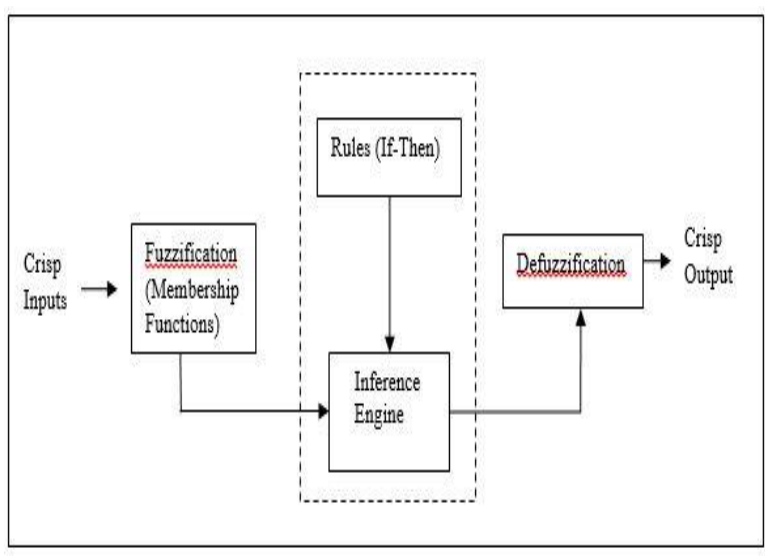

Fig 1. Generalized Fuzzy Controller [9] 


\section{PROBLEM FORMULATION}

The problem to be considered in the paper is to design fuzzy controllers for ranking the paths identified in a computer network, so that data can be transmitted faster and at the same time overhead of the network should not increase.

In this research, the paths have been ranked using fuzzy logic and better paths can be selected for data transmission on the basis of path ranks. The input for this problem is the link utilization value of each link of all paths as obtained in [10]. The input paths are identified using ITMR algorithm described [10]. The problem is to rank the paths on the basis of link utilization value of each link in each path and the hop count of the paths.

\section{FUZZY BASED MULTI-METRIC PATH RANKING SCHEME}

The multiple paths are found using the ITMR algorithm described in [10] and is presented below:

\section{Algorithm: ITMR (Intelligence Triggered Multipath Routing).}

(i) Input Source, Destination, Load, and Capacity for the input network.

(ii) path $=\{$ null $\}$.

(iii) $\mathrm{f}=0$.

(iv) $u_{i j}=0$ for all links

(v) path $=\{$ path $\}+\{$ source $\}$.

(vi) Input $\mathrm{u}_{\mathrm{thres}}$

//at the source node

(vii) $\square i \square$ neighbor of source do

$$
\begin{aligned}
& f=1 \\
& a=\text { capacity (source, } i) / \operatorname{load}(\operatorname{source}, i) \\
& \text { compute } u_{\text {source }, i}=a * u_{\text {source }, i}+(1-a) *
\end{aligned}
$$

$f$.

$$
\begin{aligned}
& \text { If } u_{\text {source }, i}<0 \\
& \text { then } u_{\text {source }, i}=0 \text {. } \\
& \text { else } \\
& \text { If } u_{\text {source }, i}<u_{\text {thres }} \text { then } \\
& \text { send pert ant to } i^{\text {th }} \text { node. } \\
& \text { path }=\{\text { path }\}+\left\{i^{\text {th }}\right.
\end{aligned}
$$

node\}

endif

end for

//At the intermediate node

(viii) $\square$ i $\square$ intermediate node(except source and destination node) do

$\square \mathrm{j} \square$ neighbor of intermediate node and does not exist in the path list do

$$
\begin{aligned}
& \mathrm{f}=1 \\
& \mathrm{a}=\text { capacity }(\mathrm{i}, \mathrm{j}) / \operatorname{load}(\mathrm{i}, \mathrm{j}) \\
& \text { compute } \mathrm{u}_{\mathrm{ij}}=\mathrm{a} * \mathrm{u}_{\mathrm{ij}}+(1-\mathrm{a}) * \mathrm{f} \\
& \text { If } \mathrm{u}_{\mathrm{ij}}<0 \text { then } \mathrm{u}_{\mathrm{ij}}=0 \\
& \text { Else } \\
& \text { If } \mathrm{u}_{\mathrm{ij}}<\mathrm{u}_{\mathrm{thres}} \\
& \text { then send Explorer message to } \mathrm{j} \text {. } \\
& \text { path }=\{\text { path }\}+\{\mathrm{jth} \text { node } \\
& \text { endif } \\
& \text { endif }
\end{aligned}
$$

end for (ix) At the destination node a fuzzy controller FITMR algorithm works to find the path ranking of all the paths which were found using ITMR algorithm and then information is sent back to source node.

(x) End.

A. Fuzzy Controller for multi-metric Ranking Scheme

Figure 2 and 3 shows the proposed Fuzzy Controllers PLU (Path Link Utilization) and PRFC (Path Ranking Fuzzy Controller) that are used to rank the paths.

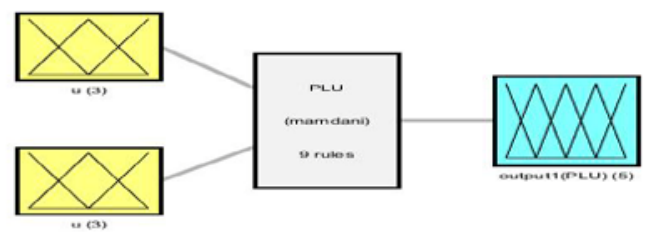

Fig. 2: The structure of Fuzzy Controller (PLU)

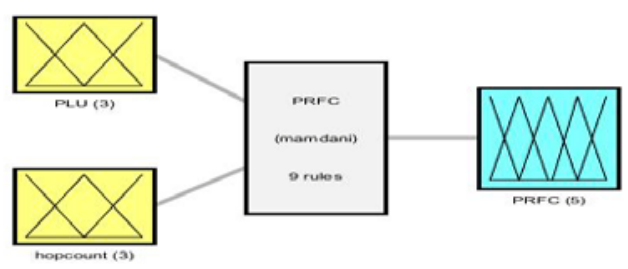

Fig. 3: The structure of Fuzzy Controller (PRFC)

Working of Fuzzy Controller is explained using FITMR (Fuzzy ITMR)

\section{Algorithm: FITMR (Fuzzy ITMR)}

i. Find all possible paths using ITMR Algorithm.

ii. Repeat steps (iii) to (v) for all paths.

iii. Link utilization value of two links of a path is input to the fuzzy controller PLU.

iv. Apply the effect of link utilization to compute the results using Mamdani Inference engine and input the computed value back to the fuzzy controller PLU until all link's link utilization value of a path is input to the fuzzy controller PLU.

v. Output of Fuzzy Controller PLU i.e. Path Link Utilization is then input to fuzzy controller PRFC along with hop count of the path. Fuzzy Controller PRFC is used to compute the crisp value for each path.

vi. Rank the paths according to crisp output i.e. Path Rank Value (PR) obtained from fuzzy controller PRFC. The path with minimum output weight is given the best rank.

vii. After finding ranks of all paths, paths are selected according to threshold value of output i.e. PR.

The Fuzzy Controllers used in the above algorithm and are shown in figures 2 and 3 are explained below: -

a) Fuzzification: The input data is fuzzified by using the triangular membership functions for both PLU and PRFC as shown in figures 4 and figures 5, 6 respectively.

//At the destination node 


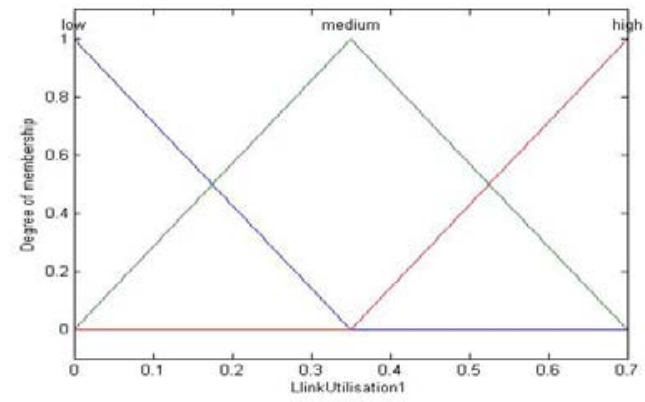

Fig. 4: Membership Function for fuzzy Inputs of PLU

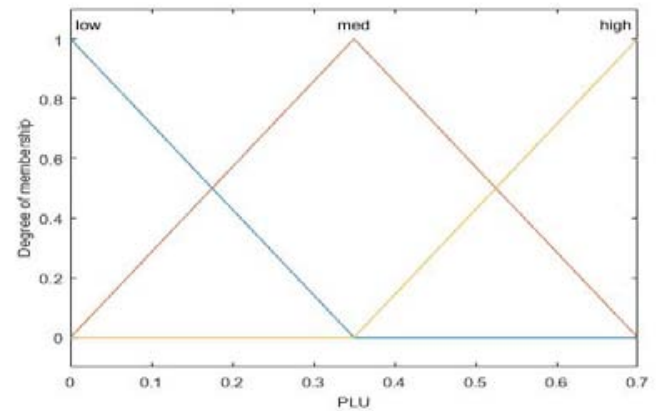

Fig. 5: Membership Function of Fuzzy Input (PLU) of PRFC

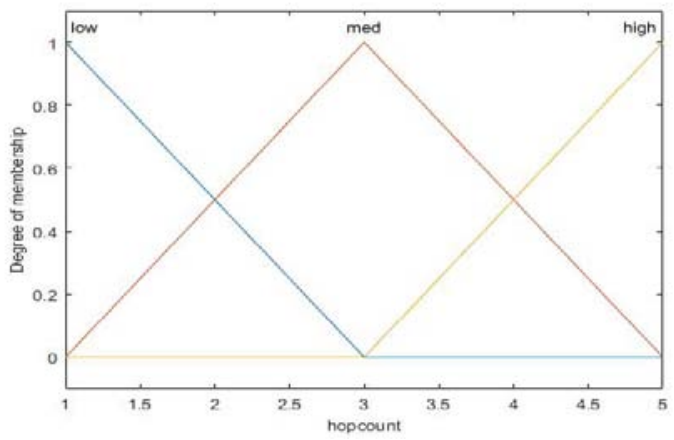

Fig. 6: Membership Function for Fuzzy Input (Hop Count) of PRFC

Input link utilizations of each link in the PLU fuzzy controller, is represented by the three sets: low, medium and high, in the range of $(0-0.7)$.

Similarly output path link utilization (PLU) is also defined by five fuzzy sets: verylow(VL), low(L), medium(M), high $(\mathrm{H})$, and veryhigh $(\mathrm{VH})$.

$\mu_{\text {link utilization }}=\left\{\mu_{\text {low }}, \mu_{\text {medium, }} \mu_{\text {high }}\right\}$

$\mu_{\text {pathlink utilization }}=\left\{\mu_{\mathrm{VL}}, \mu_{\mathrm{L}}, \mu_{\mathrm{M}}, \mu_{\mathrm{H},} \mu_{\mathrm{VH}}\right\}$

On similar lines input and output fuzzy sets with three parameters have been defined for PRFC

$\mu_{\text {pathlink utilization }}=\left\{\mu_{\text {low }}, \mu_{\text {medium, }} \mu_{\text {high }}\right\}$

$\mu_{\text {hopcount }}=\left\{\mu_{\text {low }}, \mu_{\text {medium, }} \mu_{\text {high }}\right\}$

$\mu_{\mathrm{PRFC}}=\left\{\mu_{\mathrm{VL}}, \mu_{\mathrm{L}}, \mu_{\mathrm{M}}, \mu_{\mathrm{H}}, \mu_{\mathrm{VH}}\right\}$

The output membership functions for PLU and PRFC has been shown in figures 7 and 8 respectively.

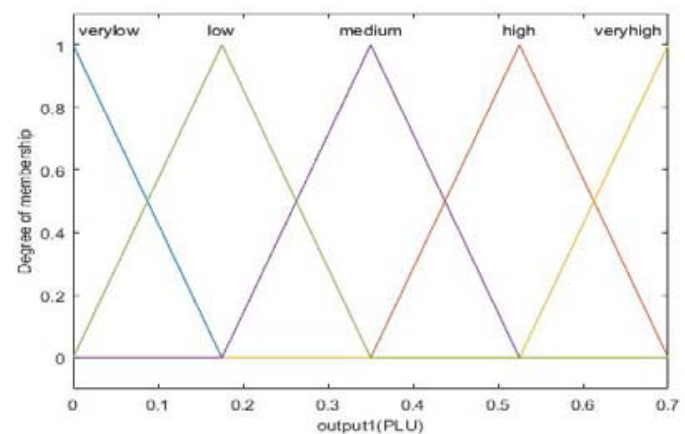

Fig. 7: Membership Function for Fuzzy Output (PLU)

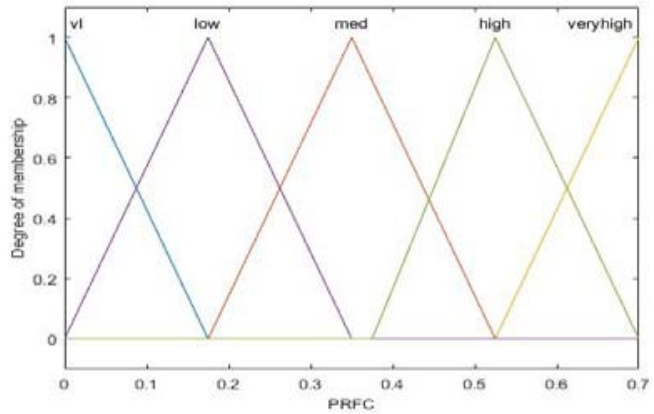

Fig. 8: Membership Function for Output (PRFC)

b) Rule Base: Rule base for PLU and PRFC have been defined in the tables I and II.

TABLE I

FUZZY RULE BASE MATRIX - PLU

\begin{tabular}{|r|l|l|l|}
\hline \multicolumn{1}{|r|}{ Link Utilization1 } & Low & Medium & High \\
\hline Low & $\begin{array}{l}\text { VL } \\
\text { Rule1 }\end{array}$ & $\begin{array}{l}\text { L } \\
\text { Rule2 }\end{array}$ & $\begin{array}{l}\text { M } \\
\text { Rule3 }\end{array}$ \\
& & & \\
\hline Medium & $\begin{array}{l}\text { L } \\
\text { Rule4 }\end{array}$ & $\begin{array}{l}\text { M } \\
\text { Rule5 }\end{array}$ & $\begin{array}{l}\text { H } \\
\text { Rule6 }\end{array}$ \\
\hline High & $\begin{array}{l}\text { M } \\
\text { Rule7 }\end{array}$ & $\begin{array}{l}\text { H } \\
\text { Rule8 }\end{array}$ & $\begin{array}{l}\text { VH } \\
\text { Rule9 }\end{array}$ \\
\hline
\end{tabular}

TABLE II

FUZZY RULE BASE MATRIX - PRFC

\begin{tabular}{|r|l|l|l|}
\hline \multicolumn{1}{|l|}{ LLU } & Low & Medium & High \\
\hline Low & & & \\
& & & \\
& VL & & \\
\hline Rule1 & Rule2 & $\begin{array}{l}\text { M } \\
\text { Rule3 }\end{array}$ \\
\hline High & $\begin{array}{l}\text { L } \\
\text { Rule4 }\end{array}$ & $\begin{array}{l}\text { M } \\
\text { Rule5 }\end{array}$ & $\begin{array}{l}\text { H } \\
\text { Rule6 }\end{array}$ \\
\hline & $\begin{array}{l}\text { Rule7 } \\
\text { Rule8 }\end{array}$ & $\begin{array}{l}\text { VH } \\
\text { Rule9 }\end{array}$ \\
\hline
\end{tabular}

Paths are decided according to the analysis of rules of rulebase and fired rules. Minimum operation is applied to find out the minimum or least value of parameters. Output response PLU value and PRFC value are obtained by applying logical product (AND) on fired rules. These fired 
rules are combined to make an optimal decision. Composition merges the possessions of all applicable rules and gives the best-weighted influence of fired rules as shown in table below.

TABLE III: RULES TRIGGERING TABLE

\begin{tabular}{|l|l|}
\hline Input & Output Linguistic variable \\
\hline PLU & VL=Rule1 \\
& L=Rule2+Rule4 \\
& M=Rule3+Rule5+Rule7 \\
& H=Rule6+Rule8 \\
& VH= Rule9 \\
\hline PRFC & VL=Rule1 \\
& L=Rule2+Rule4 \\
& M=Rule3+Rule5+Rule7 \\
& H=Rule6+Rule8 \\
& VH= Rule9 \\
\hline
\end{tabular}

The rule structure formulation is based on the consideration that minimum value for PRFC in the fuzzy scheme is assumed to be the best path.

c) Defuzzification: Centriod method has been used for both the fuzzy controllers for defuzzification. The lower crisp values of the paths are considered as better paths.

$$
\mu_{\mathrm{CA}}=\sum_{i=1}^{n} \mu \mathrm{xi} * \mathrm{x}_{\mathrm{ci}} / \sum_{i=1}^{n} \mu \mathrm{xi}
$$

This is an approximation of center of Area (CoA) defuzzifier method. $\mathrm{X}_{\mathrm{ci}}$ denotes the center points of output linguistic terms $\mathrm{xi}, \mu_{\mathrm{CA}}$ is membership function of output linguistic term and $\mu_{\mathrm{xi}}$ is membership function value of input linguistic terms and linguistic centers of control systems, PLU are obtained as shown in table IV below.

TABLE IV: DEFUZZIFICATION OF FUZZY CONTROLLERS

\begin{tabular}{|c|c|c|c|}
\hline $\begin{array}{l}\text { Output } \\
\text { parameter }\end{array}$ & $\begin{array}{l}\text { Linguistic } \\
\text { term }\end{array}$ & $\begin{array}{l}\text { Linguistic } \\
\text { centre }\end{array}$ & Defuzzified value \\
\hline PLU & $\begin{array}{l}\mathrm{VL} \\
\mathrm{L} \\
\mathrm{M} \\
\mathrm{H} \\
\mathrm{VH}\end{array}$ & $\begin{array}{l}\mathrm{VL}_{\mathrm{c}} \\
\mathrm{L}_{\mathrm{c}} \\
\mathrm{M}_{\mathrm{c}} \\
\mathrm{H}_{\mathrm{c}} \\
\mathrm{VH}_{\mathrm{c}}\end{array}$ & $\begin{array}{l}\mathrm{PLU}_{\text {value }}=(\mathrm{VL} * \\
\mathrm{VL}_{\mathrm{c}}+\mathrm{L} * \mathrm{~L}_{\mathrm{c}}+\mathrm{M} \\
* \mathrm{M}_{\mathrm{c}}+\mathrm{H} * \mathrm{H}_{\mathrm{c}}+ \\
\left.\mathrm{VH} * \mathrm{VH}_{\mathrm{c}}\right) /(\mathrm{VL} \\
+\mathrm{L}+\mathrm{M}+\mathrm{H}+ \\
\mathrm{VH})\end{array}$ \\
\hline PRFC & $\begin{array}{l}\text { VL } \\
\mathrm{L} \\
\mathrm{M} \\
\mathrm{H} \\
\mathrm{VH}\end{array}$ & $\begin{array}{l}\mathrm{VL}_{\mathrm{c}} \\
\mathrm{L}_{\mathrm{c}} \\
\mathrm{M}_{\mathrm{c}} \\
\mathrm{H}_{\mathrm{c}} \\
\mathrm{VH}_{\mathrm{c}}\end{array}$ & $\begin{array}{l}\mathrm{PRFC}_{\mathrm{value}}=(\mathrm{VL} * \\
\mathrm{VL}_{\mathrm{c}}+\mathrm{L} * \mathrm{~L}_{\mathrm{c}}+\mathrm{M} \\
* \mathrm{M}_{\mathrm{c}}+\mathrm{H} * \mathrm{H}_{\mathrm{c}}+ \\
\left.\mathrm{VH} * \mathrm{VH}_{\mathrm{c}}\right) /(\mathrm{VL} \\
+\mathrm{L}+\mathrm{M}+\mathrm{H}+ \\
\mathrm{VH})\end{array}$ \\
\hline
\end{tabular}

\section{EXPERIMENTAL SETUP AND RESULTS}

The proposed algorithm is implemented for the network shown in figure 9 using MATLAB. The network considered is having six nodes. In this network, the capacity is considered to be fixed at 10 and the load is displayed for each link.

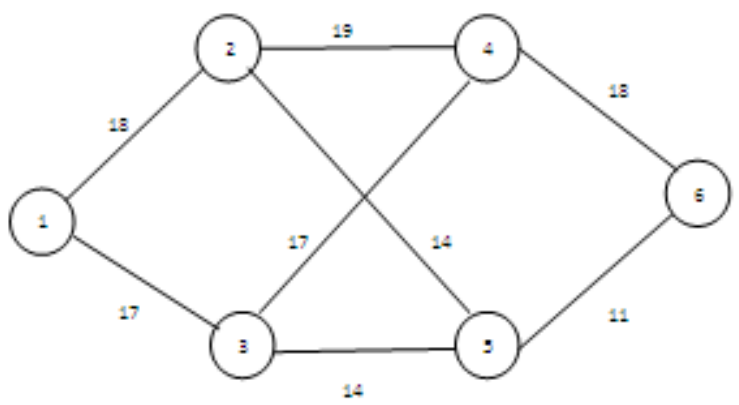

Fig. 9: Example Network [10]

A total number of six paths were found using ITMR algorithm. The paths and their link utilization value are shown in table V:

TABLE V

PATHS AND LINK UTILIZATION VALUES FOUND USING ITMR [10]

\begin{tabular}{|l|l|}
\hline Path Identified & $\begin{array}{l}\text { Link Utilization Values over the } \\
\text { Links }\end{array}$ \\
\hline $1-2-4-6$ & $0.444,0.473,0.444$ \\
\hline $1-3-4-6$ & $0.411,0.411,0.691$ \\
\hline $1-2-5-6$ & $0.444,0.489,0.090$ \\
\hline $1-3-5-6$ & $0.411,0.489,0.173$ \\
\hline $1-2-4-3-5-6$ & $0.444,0.473,0.411,0.489,0.248$ \\
\hline $1-3-4-2-5-6$ & $0.411,0.411,0.473,0.489,0.316$ \\
\hline
\end{tabular}

The link utilization values of the paths were then found using FITMR and are shown in the table VI:

TABLE VI

PLU FOUND USING FITMR [10]

\begin{tabular}{|l|c|}
\hline Path & Path Link Utilization Value \\
\hline $1-2-4-6$ & 0.472 \\
\hline $1-3-4-6$ & 0.520 \\
\hline $1-2-5-6$ & 0.287 \\
\hline $1-3-5-6$ & 0.311 \\
\hline $1-2-4-3-5-6$ & 0.339 \\
\hline $1-3-4-2-5-6$ & 0.378 \\
\hline
\end{tabular}

The ranking of paths using path link utilization is depicted in table VII.

TABLE VII

RANKING OF THE PATHS USING PLU

\begin{tabular}{||l||l|l||}
\hline \hline Path & $\begin{array}{l}\text { Path Link Utilization } \\
\text { Value }\end{array}$ & Rank \\
\hline \hline $1-2-4-6$ & 0.472 & 5 \\
\hline \hline $1-3-4-6$ & 0.520 & 6 \\
\hline \hline $1-2-5-6$ & 0.287 & 1 \\
\hline \hline $1-3-5-6$ & 0.311 & 2 \\
\hline \hline $1-2-4-3-5-6$ & 0.339 & 3 \\
\hline \hline $1-3-4-2-5-6$ & 0.378 & 4 \\
\hline
\end{tabular}

Final ranking of the paths is found by using path link utilization value and hop-count to the PRFC controller. Results obtained are shown in table VII. 
TABLE VII

RANKING OF THE PATHS USING PRFC

\begin{tabular}{|l|l|l|l|l|}
\hline Path & PLU & $\begin{array}{l}\text { Hop } \\
\text { count }\end{array}$ & $\begin{array}{l}\text { PR } \\
\text { Value }\end{array}$ & Rank \\
\hline $1-2-4-6$ & 0.472 & 3 & 0.416 & 3 \\
\hline $1-3-4-6$ & 0.520 & 3 & 0.435 & 4 \\
\hline $1-2-5-6$ & 0.287 & 3 & 0.311 & 1 \\
\hline $1-3-5-6$ & 0.311 & 3 & 0.324 & 2 \\
\hline $1-2-4-3-5-6$ & 0.339 & 5 & 0.524 & 5 \\
\hline $1-3-4-2-5-6$ & 0.378 & 5 & 0.534 & 6 \\
\hline
\end{tabular}

\section{INTERPRETATION OF THE RESULTS}

It is observed from the results that by adding hop-count as a metric for finding the paths ranking, the paths having more number of hops are ranked lower than the paths having lesser number of hops. When the two tables 7 and 8 are compared, it can be easily observed that the paths 1-2-4-3-56 and 1-3-4-2-5-6 were having better ranks when only link utilization was taken into account. As soon as hop-count was added, the ranking of these paths get lowered. However, the ranking of the paths having similar number of hops remains unaffected.

\section{CONCLUSION}

A fuzzy controller PRFC has been proposed in this paper. The controller uses two metrics link utilization and hopcount for calculating the ranking of the paths. The multiple paths are identified using ITMR and their rankings are found initially by using PLU and then PRFC. It may be concluded that when both link utilization and hop-count were considered, the paths having lesser link utilization and less number of hops were found to be having lesser fuzzy values and better path ranking. These results were different from the PLU based ranking only when the hop-count was different i.e., the lesser hop-count yields a better ranking.

\section{REFERENCES}

[1] Shalini Aggarwal and Shuchita Upadhyaya, "Exploring Mutiple Paths using Link Utilization in Computer Networks", IJCNS International Journal of Computer Science and Networks, Vol.5, Issue 5, October, 2016, ISSN(online) 2277-5420.

[2] Chiang Kang Tan, Lionel Sacks, "The Use of Fuzzy Metric in OSPF Network", http://www.ee.ucl.ac.uk/ /sacks/projects/pastproj/ck_tan.pdf. August 3, 2001.

[3] Resende R A, Rossi S M, Yamakami A and Bonani L H, "Traffic Engineering with MPLS using Fuzzy Logic for Applications in IP Networks”, IEEE International Conference, 2003, pp. 1146-1151

[4] Yaghmaee M H, Baradaran M, Talebain H, “A Fuzzy QoS Routing Algorithm for Communication Networks", IEEE Singapore International Conference on Communication System, 2006

[5] Din N M, Abidin H Z, Rahman S F A and Fisal N, "A Fuzzy LSP Regulator for Preemption Control in a DiffServ Aware MPLS Internat”, IEEE Malaysia International Conference, 2005, pp. 415-420

[6] Din N M and Fisal N, "Fuzzy Logic Bandwidth Prediction and Policing in a DiffServ-Aware Network", Journal of Computers, Vol. 3, Issue 5, 2008, pp. 18-20

[7] Khan J A and Alnuweiri H, "A Fuzzy Constraint-Based Routing Algorithm for Traffic Engineering”, IEEE Communications Society, 2004, pp. 1366-1372

[8] P. Chemouil, J. Khalfet and M. Lebourges (1995), “A Fuzzy Control Approach for Adaptive Routing”, IEEE Commmunications Magazine, 33(7), pp 70-76, July.

[9] Poonam, C.K. Nagpal, and Shailender Gupta " A Delay and Spectrum Aware Fuzzy Logic Based Routing Protocol for CRN”, published in International Journal of Computer Network and Applications, IJCNA-2016, Vol.-3(1),pp.16-24.

[10] Shalini Aggarwal and Shuchita Upadhyaya, “ Fuzzy based Link Utilization Aware Path Ranking Scheme for Multipath Routing” International Journal of Advanced Research in Computer and Communication Engineering (IJARCCE), Vol.5, Issue 10, October, 2016, pp. 409-413 